\title{
Detection of the Oyashio and Kuroshio fronts under the projected climate change in the 21st century
}

\author{
Haruka Nishikawa ${ }^{1 *} \mathbb{D}$, Shiro Nishikawa', Hiroshi Ishizaki', Tsuyoshi Wakamatsu' ${ }^{2,3}$ and Yoichi Ishikawa'
}

\begin{abstract}
We evaluate the Oyashio and Kuroshio fronts latitudinal transition under the projected climate change scenarios using eddy resolving regional ocean climate projection products from 1981 to 2100 . The regional ocean climate projections are produced based on dynamical downscaling of four CMIP5 models and two RCP experiments RCP2.6 and RCP8.5. Two approaches of the fronts detection methods are compared. One is conventional approach based on subsurface specific isotherm and another is newly proposed approach based on the Oyashio and Kuroshio water temperature and salinity (TS) profiles that may change as the global warming progresses. It is found that the Oyashio TS profile rapidly shift to be high both in temperature and salinity in RCP8.5 cases while the Kuroshio TS profile shows small change toward the end of the twenty-first century in all cases. Northward shift of the Oyashio and Kuroshio fronts reaches $2^{\circ}$ northward by the late twenty-first century in extreme case of RCP 8.5 cases from the temperature-based definition. On the other hand, the northward shifts of fronts are less than $1^{\circ}$ when we use the TS-based definition. The comparison of both fronts positions with the surface velocity distributions suggest that the TS-based definition captures transitions of the fronts better than the temperature-based definition.
\end{abstract}

Keywords: Global warming, Climate projection, Kuroshio, Oyashio

\section{Introduction}

Oyashio is the western boundary current and its extension of the western subarctic gyre in the North Pacific Ocean (Fig. 1). A part of East Kamchatka Current (EKC) flows into the Okhotsk Sea in the northern Kuril Straits and is then mixed with Okhotsk Sea Mode Waters (OSMW). This is the origin of the Oyashio water. Oyashio flows southward along Japanese coast and its south western edge reaches off Tohoku region. Turning eastward off the Tohoku region, Oyashio current follows the Sub-Arctic Front (SAF) characterized by the temperature front and forms the Oyashio extension or the Subarctic Current (Zhang and Hanawa 1993). South of the Oyashio front lies the Kuroshio front associated with Kuroshio and its

\footnotetext{
* Correspondence: harukan@jamstec.go.jp

${ }^{1} J a p a n$ Agency for Marine-Earth Science and Technology, 3173-25

Showa-machi, Kanazawa-ku, Yokohama, Kanagawa 236-0001, Japan

Full list of author information is available at the end of the article
}

extension, Kuroshio Extension (KE), a strong westward boundary current of the North Pacific Ocean subtropical circulation. Area between the Oyashio front and the Kuroshio front, the Kuroshio-Oyashio Transition Zone (KOTZ), is known to be highly productive fishing grounds. Nutrient-rich Oyashio waters sustain large stocks of small pelagic fish (e.g., Pacific saury, Japanese sardine) while the warm Kuroshio waters provide them winter spawning grounds. The small pelagic fish migrate seasonally between the Kuroshio waters for spawning and the Oyashio waters for growing in KOTZ. In autumn, fishing vessels in Tohoku region can catch fat fish that is migrating from the Oyashio waters to the Kuroshio waters in their neighborhood ocean. KOTZ is also important for fish stock itself. Recruitment of the Pacific saury varies with the spring productivity in this region through the larvae survival rate (Ichii et al. 2018).

\section{Springer Open}

( ) The Author(s). 2020 Open Access This article is licensed under a Creative Commons Attribution 4.0 International License, which permits use, sharing, adaptation, distribution and reproduction in any medium or format, as long as you give appropriate credit to the original author(s) and the source, provide a link to the Creative Commons licence, and indicate if changes were made. The images or other third party material in this article are included in the article's Creative Commons licence, unless indicated otherwise in a credit line to the material. If material is not included in the article's Creative Commons licence and your intended use is not permitted by statutory regulation or exceeds the permitted use, you will need to obtain permission directly from the copyright holder. To view a copy of this licence, visit http://creativecommons.org/licenses/by/4.0/. 


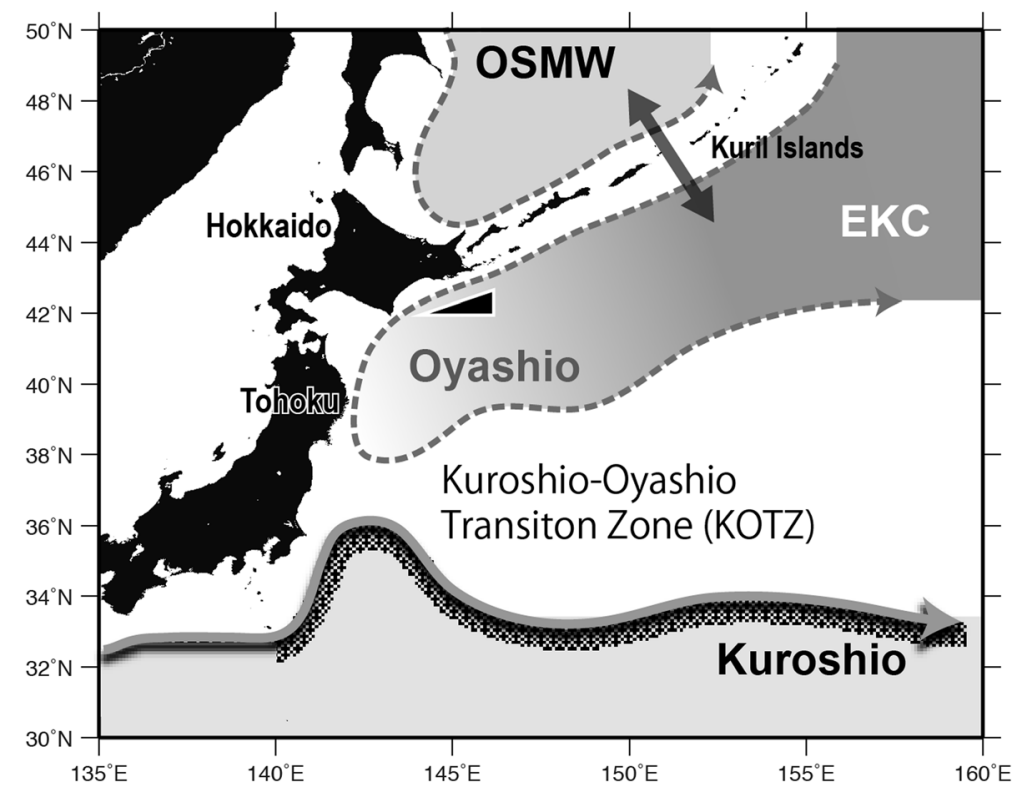

Fig. 1 Schematic diagram of the Kuroshio and Oyashio. Oyashio is a mixture of the East Kamchatka Current (EKC) and Okhotsk Sea Mode Water (OSMW) that outflows to the Pacific through the Kuril Straits. The black triangle represents the area where we picked up waters as the pure Oyashio water and the shaded area below the Kuroshio (gray arrow) represent the area where we picked up waters as the pure Kuroshio water

Since KOTZ is defined as an area that lies between the Oyashio and Kuroshio fronts, evaluation of its transition under the climate change requires concurrent analysis of both fronts. If the both Oyashio and Kuroshio fronts shift northward, the transition zone will shift northward, and if the only Kuroshio front shifts north, the area of transition zone will reduce. These changes should have serious impacts on migration ecology and stock level of fish and fishing industry. Inter-annual to decadal time scale variation of the Oyashio and Kuroshio fronts can be explained mainly by linear dynamics of wind-driven ocean circulation theory (Seager et al. 2001). There are some studies on the future projection of Kuroshio front under the climate change. Most of studies suggested that the Kuroshio front will shift north along with the Kuroshio intensification (Sato et al. 2006; Yang et al. 2016; Li et al. 2017) and one study suggested that the Kuroshio front location will not change (Sakamoto et al. 2005). In contrast, there are no studies conducted on the Oyashio front transition under the climate change to authors' knowledge.

In general, realistic representation of the Oyashio and Kuroshio fronts and associated complex water mass properties in KOTZ in numerical simulation requires eddy-resolving horizontal resolution (e.g., Hurlburt et al. 1996). However, the resolution of most of ocean components in CMIP5 models are in the range of $1-2^{\circ}$ and their horizontal resolutions are too coarse to reproduce KOTZ and its associated fronts. In this study, we investigated how the Oyashio and Kuroshio fronts will shift under the climate change by using high-resolution future ocean regional projections based on the fifth phase of the Climate Model Intercomparison Project (CMIP5) products. The new regional ocean projections have 10 $\mathrm{km}$ horizontal resolution which is high enough to represent the Oyashio and Kuroshio fronts in realistic manner. Combinations of four models and two experiments are chosen from CMIP5 multi model ensemble datasets and this is the first model intercomparison study of the Oyashio and Kuroshio fronts transition under the climate change.

Since the Oyashio front and the Kuroshio front are both characterized by strong surface current as extensions of subpolar and subtropical western boundary currents, the best way to identify the location of both fronts are to follow the associated strong surface current axis. The most reliable Kuroshio front location, which is reported by the Japan Coast Guard (JCG), is estimated by various observation data. They see the velocity, temperature, and sea surface height $(\mathrm{SSH})$ distribution collected by national patrol boats, merchant vessels, buoys, radars, and satellites and finally they decide the location by hand. However, such works take a lot of time. For that reason, the locations of the Oyashio and Kuroshio fronts are conventionally defined based on respective specific isotherm at reference depth because both fronts are characterized by temperature fronts.

Under the current climate condition, the Oyashio front roughly follows $5{ }^{\circ} \mathrm{C}$ isotherm at $100 \mathrm{~m}$ depth and the Kuroshio front roughly follows $14-15{ }^{\circ} \mathrm{C}$ isotherm at $200 \mathrm{~m}$ depth (Kawai 1972). These definitions are the 
most popular because they are more practical and robust than other definitions (e.g., using sea surface height gradient or sea surface temperature) and the defined fronts correspond well to the core of the surface velocity (Kida et al. 2015). Many studies (e.g., Masujima et al. 2003; Kouketsu et al. 2005; Kakehi et al. 2017), and government offices (e.g., Japan Meteorological Agency, Fisheries Research, and Education Agency Japan) used these definitions. Also, previous studies for the climate change adopt these definitions (e.g., Yokouchi et al. 2006). However, we expect that this conventional approach would not be effective for front detection in the future projection products, since the specific index temperature associated with each front gradually changes as the climate change progresses.

We propose new front detection method that uses both temperature and salinity profiles. Then we compare transition of KOTZ and associated fronts distribution evaluated by the two front detection methods, conventional method (henceforth temperature-based) and newly proposed method (henceforth TS-based). We focused on spring season (April-May) when the Oyashio front shows seasonal southward shift and the period is an important season for growing and migration of small pelagic fish. This paper is organized as follows. Production of the regional projection of ocean state by dynamical downscaling of CMIP5 products and the front detection methods are descried in "Methods/Experimental" section. Evaluation of the TS properties and detected front locations using the regional ocean projection data set are made in "Results" section. General remarks on our front detection methods and their impact of to the evaluation of the KOTZ production are briefly discussed.

\section{Methods/Experimental}

\section{Future ocean regional projection datasets}

High-resolution future ocean regional projection (FORP) products over the North Pacific domain (Nishikawa et al. 2020) are generated by dynamically downscaling CMIP5 global ocean future projection products (Taylor et al. 2012). Four models, MIROC5, MRI-CGCM3, GFDL-ESM2M, and IPSL-CM5A-MR, and three experiments, historical (1960-2005), RCP2.6 (2006-2100), and RCP8.5 (2006-2100), are selected from CMIP5 database based on representativeness of Kuroshio separation and KE latitudes judged from sea surface temperature map and availability of three hourly atmospheric parameters necessary to construct atmospheric external forcings to drive an ocean circulation model. For dynamical downscaling of the CMIP5 products, we configured ocean general circulation model MRI.COMv4 (Tsujino et al. 2017) over the North Pacific domain (NP10: $15^{\circ}$ S-70 ${ }^{\circ}$ $\left.\mathrm{N}, 100^{\circ} \mathrm{E}-75^{\circ} \mathrm{W}\right)$ with $10 \mathrm{~km}$ horizontal resolution and 54 vertical levels (Fig. 2). NP10 domain has three open boundaries at its west, south, and north boundaries and model temperature and salinity within $2^{\circ}$ band along each boundary are restored to prescribed monthly mean temperature and salinity data gridded on the World Ocean Atlas (WOA) standard grid with $1^{\circ}$ horizontal resolution and 33 levels.

The monthly mean temperature and salinity data at the model boundaries during CMIP5 historical run period (1960-2005) are derived from World Ocean Atlas 94 (WOA94) database (Levitus and Boyer 1994; Levitus et al. 1994). At the end of the historical run period, the boundary values are switched from WOA to an interannual monthly mean data constructed by merging CMIP5 ocean products (1996-2100) and the WOA product. First, CMIP5 temperature and salinity data are regridded to the common WOA grid and 21 years climatological monthly mean data over the period of 1996-2015 are derived. Merger of WOA and CMIP5 products is achieved by replacing the monthly mean field of each CMIP5-derived monthly mean field by WOA monthly mean field during RCP experiment period (2006-2100). The period is chosen so that jump of boundary values from end of historical run to RCP runs after 2006 is minimized. At last, 11 years running mean filter is applied to the merged boundary values at each monthly bin.

Sets of external forcing for driving the ocean model is constructed from CMIP5 surface atmospheric parameters: $2 \mathrm{~m}$ air temperature; $2 \mathrm{~m}$ specific humidity, surface pressure, surface solar radiation flux, surface long wave flux, precipitation flux; $10 \mathrm{~m}$ zonal wind; and $10 \mathrm{~m}$ meridional wind at three hourly temporal resolution and sea level pressure at six hourly resolution for each CMIP5 model and experiment. The atmospheric parameters are regridded to common spherical coordinate of $0.5^{\circ}$ horizontal resolution. Then 5 days running average filter is applied to the regridded parameters at each three hourly temporal bin for reducing high-frequency noise in order to increase stability of long-term integration of the ocean model. Freshwater flux from precipitation rate is converted to salt flux internally in the ocean model and the model integration is conducted with volume conservation constraint.

Freshwater inputs from rivers are not considered and sea surface salinity (SSS) is restored to the WOA climatological monthly mean salinity in all experiments. The SSS restoration is introduced for avoiding SSS drift in basin scale commonly experienced by the ocean circulation model driven by climatological or reanalysis atmospheric forcing. We have used 2 days as the restoration time scale. We do not restore the model SSS to the corresponding CMIP5 ocean salinity products for several reasons. The main reason is that CMIP5 ocean model has coarse horizontal resolution of order of $1^{\circ}$ to $2^{\circ}$ and 


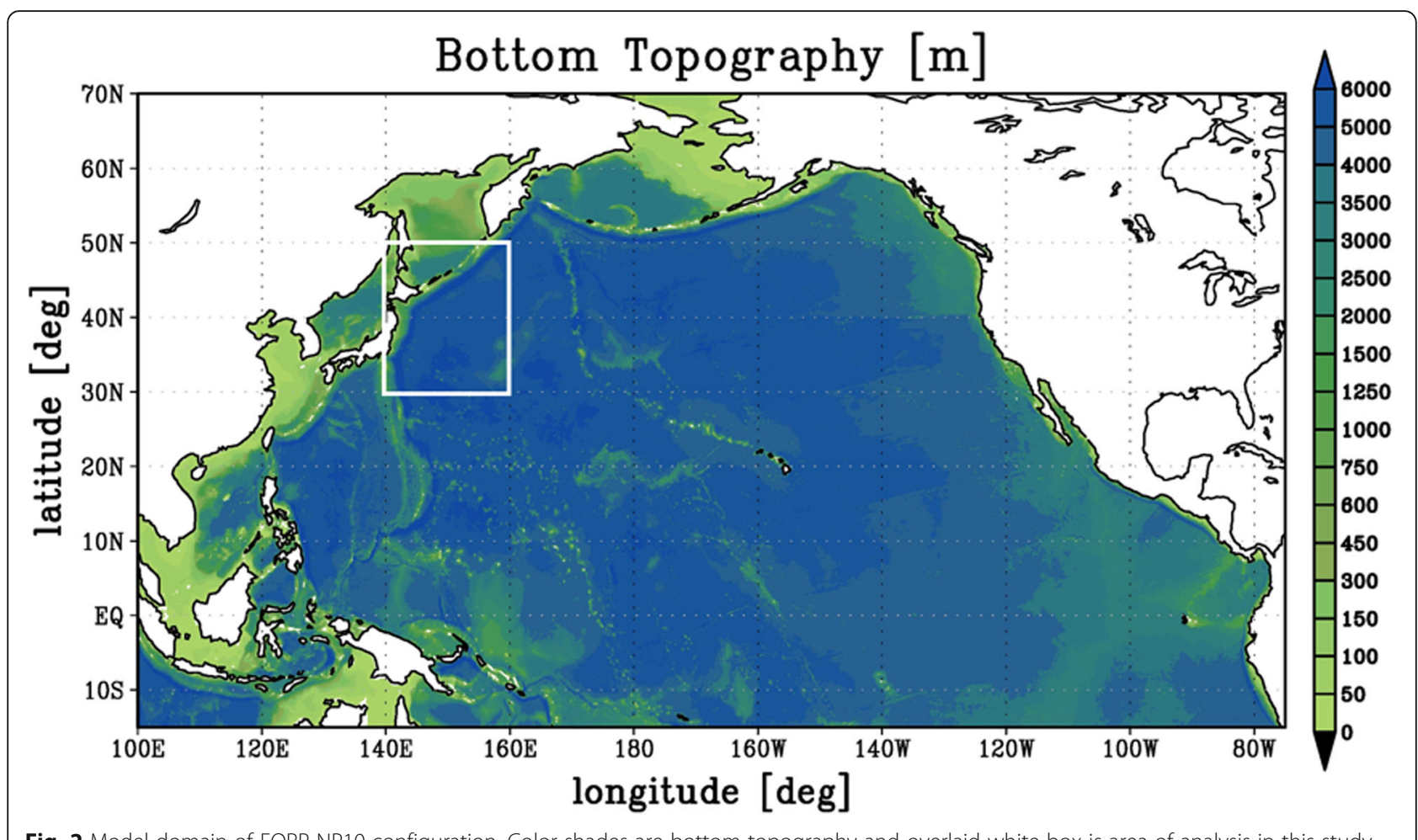

Fig. 2 Model domain of FORP-NP10 configuration. Color shades are bottom topography and overlaid white box is area of analysis in this study

western boundary currents such as Kuroshio and Oyashio are not well represented compared to FORP-NP10 with resolution of order $1 / 10^{\circ}$. Because of this large discrepancy between the original CMIP5 ocean model and FORP-NP10, CMIP5 SSS has spatial distribution unmatched to the circulation pattern represented in FORPNP10 and level of the discrepancy differs among the CMIP5 models and scenarios. In order to make the downscaling experimental settings as common as possible, we chose the WOA SSS as a common SSS product for the restoration.

Ocean model starts from the rest initialized with the WOA January mean temperature and salinity and integrated with the CMIP5-derived atmospheric forcing from 1960 to 2100. After 20 years spinning-up run period, we saved monthly mean oceanic parameters, temperature, salinity, SSH, velocity fields, and surface forcing fields from 1981 to 2100. We call this regional future ocean projection product, FORP-NP10, hereafter. In this study, we use monthly mean temperature, salinity, and horizontal velocity fields from FORP-NP10 over the period from 1981 to 2100 . In order to test the newly proposed front detection method under the current climate condition, we also use temperature, salinity, and velocity from four-dimensional variational ocean reanalysis for the Western North Pacific Ocean, FORA-WNP (Usui et al. 2017). FORA-WNP shares the same horizontal grid and vertical grid coordinates with FORP-NP10 over the analysis domain depicted in Fig. 2.

\section{Front detection methods}

The conventional approach, which regards the Oyashio front roughly follows $5{ }^{\circ} \mathrm{C}$ isotherm at $100 \mathrm{~m}$ depth and the Kuroshio front roughly follows $14-15{ }^{\circ} \mathrm{C}$ isotherm at $200 \mathrm{~m}$ depth, was applied to temperature data of FORAWNP on April 2002. As can be confirmed in Fig. 3, the detected Oyashio and Kuroshio fronts match well with the KE and the SAF accompanying eastward strong surface currents. However, in evaluating future transition of the Oyashio and Kuroshio fronts, the conventional method to detect front distribution based on target isotherm line would become infeasible due to basin-wide upper ocean temperature rise expected under the projected climate change. Thus, detection of both fronts would require alternative approach. Here, we propose a new method for detecting the Oyashio and Kuroshio fronts based on TS profiles of the Oyashio and Kuroshio waters. We picked up waters in a triangle area (143.5$146^{\circ} \mathrm{E}$ and $42-43^{\circ} \mathrm{N}$ ) in Fig. 1 as the area where standard Oyashio water can be found due to its closeness to the region where the EKC is mixed with OSMW to form the Oyashio water. We define standard TS profile of the pure Oyashio water by water properties within the triangle. Detecting the $\mathrm{KE}$ axis from the surface velocity field, we define wasters found within $0-50 \mathrm{~km}$ south of the Kuroshio axis and within 140-160 E longitudinal band as standard TS profile of the pure Kuroshio waters (shaded area in Fig. 1). TS profiles of the pure Oyashio 


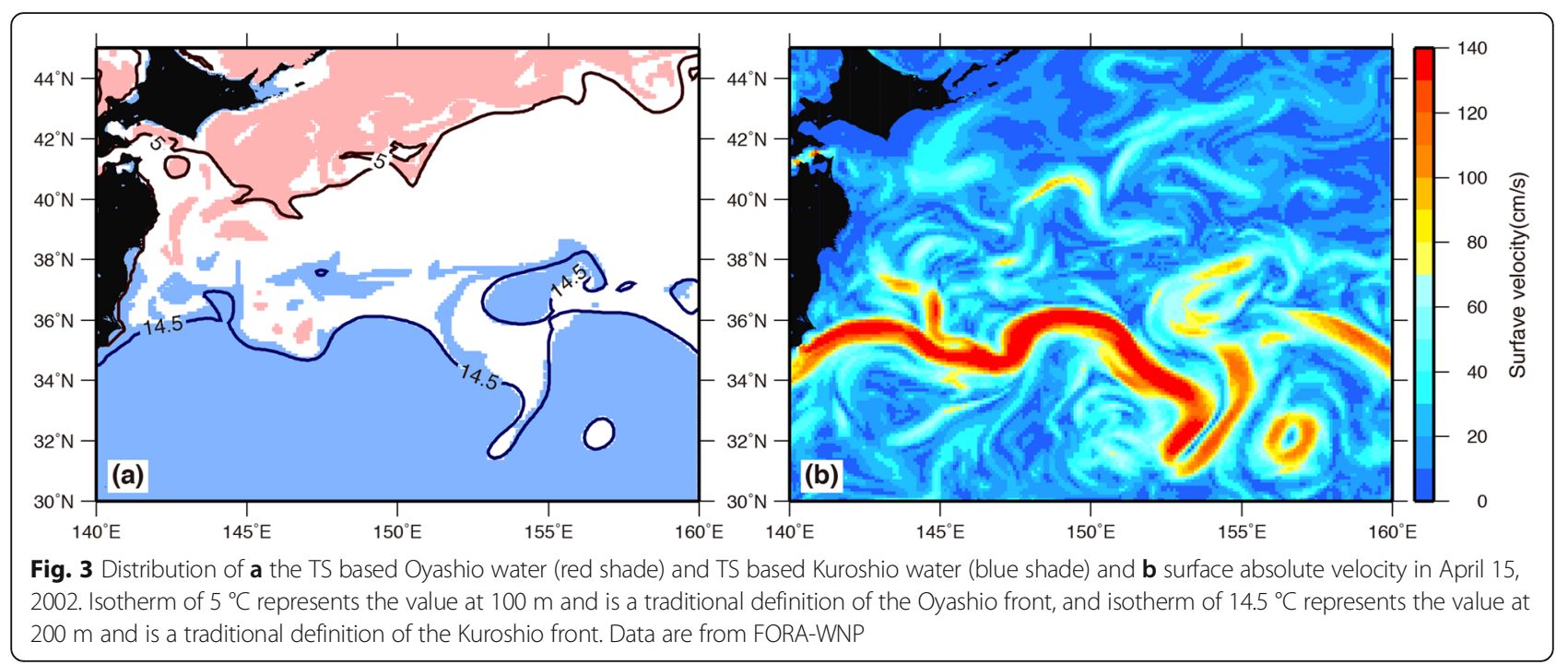

and pure Kuroshio waters (solid lines in Fig. 4) defined this manner from FORA-WNP during the period 19812015 correspond well to TS profiles of observed Oyashio and Kuroshio waters (cross marks in Fig. 4).

We calculated each TS profiles of FORP-NP10 in April and May from 2006 to 2100 and averaged them every 20

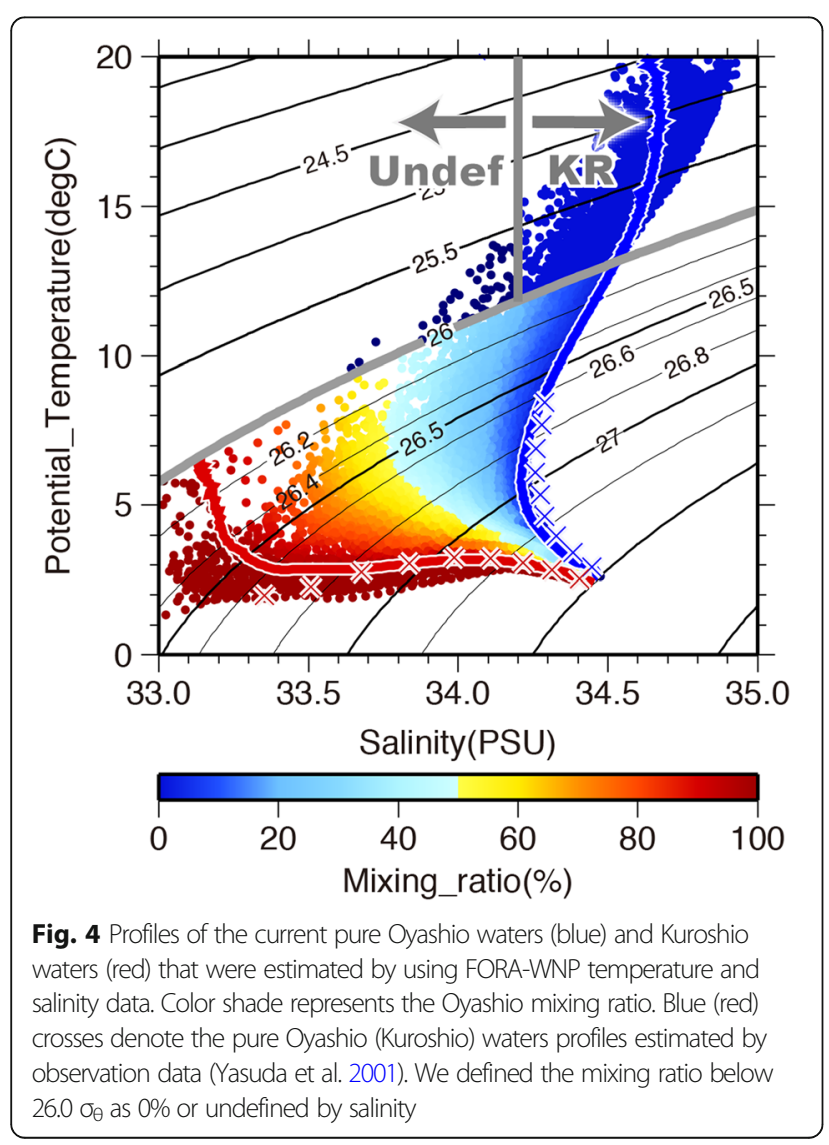

years period. But only first period is from 2006 to 2020 . Then we interpolated the TS profile sets $(2006-2020, \ldots$, 2081-2100) to estimate the yearly TS profiles. The reason why we use averaging and interpolation is that we focus on describing decadal time scale transitions of the Oyashio and Kuroshio fronts. Next, we calculated the ratio of Oyashio-Kuroshio mixing ratio of the water at $300 \mathrm{~m}$ depth over the rectangular domain $\left(143-160^{\circ} \mathrm{E}, 30-50^{\circ}\right.$ $\mathrm{N})$ depicted in Fig. 2. Waters in the target area are the Oyashio water, Kuroshio water, or mixture of these waters (see Fig. 4), and the Oyashio-Kuroshio mixing ratio is calculated by using TS profiles (Shimizu et al. 2001).

Since low-density Kuroshio water sometimes runs over high density Oyashio water (Nishikawa et al. 2016), the fronts position varies with depth. Also the TS profiles of pure Oyashio and Kuroshio waters change slightly during the transportation. For that reason, we tested the Oyashio-Kuroshio mixing ratio in some depths to find the most suitable criteria for fronts detection. Consequently, we defined the waters with larger than $90 \%$ of the Oyashio-Kuroshio mixing ratio at $300 \mathrm{~m}$ depth as the Oyashio waters and the waters with smaller than $5 \%$ of the Oyashio-Kuroshio mixing ratio at $300 \mathrm{~m}$ depth as the Kuroshio waters. This definition mostly corresponds to the Oyashio and Kuroshio fronts distribution that are suggested by velocity, temperature, and salinity distribution. Then we detect the Oyashio and Kuroshio fronts as south and north limits of each waters in each longitude. This definition of fronts is named as "TS-based." We also use the conventional way to detect the fronts. We regarded the isotherm of $5{ }^{\circ} \mathrm{C}$ at $100 \mathrm{~m}$ as the Oyashio front and regarded the isotherm of $14.5^{\circ} \mathrm{C}$ at $200 \mathrm{~m}$ as the Kuroshio front. This definition is named as "temperature-based." Then we analyze mean latitudes of the Oyashio and Kuroshio fronts from $143^{\circ} \mathrm{E}$ to $160^{\circ} \mathrm{E}$ in this study. 
We compared the "TS-based" and "temperaturebased" front detection methods in the current climate state. Figure $3 \mathrm{a}$ is an example of the comparison made in April 2002 using FORA-WNP data. In the TS-based definition, the Oyashio front in $145^{\circ} \mathrm{E}$ is at $38.7^{\circ} \mathrm{N}$ and the Kuroshio front in $155^{\circ} \mathrm{E}$ is located at $38.0^{\circ} \mathrm{N}$ since we picked up the minimum and maximum latitude of the Oyashio and Kuroshio waters. The Oyashio and Kuroshio fronts locations detected from the two methods distribution are mostly the same in the current climate state. It can be also confirmed that both Oyashio and Kuroshio fronts locations are also consistent with the KE and the SAF, respectively based on the surface current structure (Fig. 3b).

\section{Results}

\section{Sverdrup transport stream function of CMIP5 forcing}

In order to characterize differences among the selected CMIP5 forcing regarding their expected impact to the Kuroshio and Oyashio fronts, the Sverdrup transport stream function (STSF) is calculated from 10 years annual mean and winter (December, January, and February) mean wind stress for each CMIP5 forcing. Time series of the latitude of zero STSF measured at $160^{\circ} \mathrm{E}$ are plotted in Fig. 5. The latitude of zero STSF represents the border of sub-tropical and sub-polar gyres expected from the linear wind-driven ocean circulation theory. More specifically, the zero STSF latitudes based on winter mean wind stress and annual mean wind stress correspond to the Kuroshio front and the subarctic (Oyashio) front (Hurlburt et al. 1996), respectively.
The winter mean wind-stress derived zero STSF latitudes under RCP8.5 scenario during the future projection period (2005-2100) shows two distinct patterns: (i) no significant trend in MRI-CGCM3 and IPSL-CM5AMR and (ii) poleward shift of about 2 to $3^{\circ}$ in MIROC5 and GFDL-ESM2M. The same patterns can be found in the annual mean wind-stress derived STSF latitudes with larger poleward shifts of about $4^{\circ}$ in MIROC5. There is no clear trend in STSF latitudes in all cases under RCP2.6 scenario. Thus from CMIP5 wind stress, significant poleward shift of both Kuroshio and Oyashio fronts in the FORP-NP10 products is expected to be seen in MIROC5 and GFDL-ESM2M under RCP8.5 scenario.

\section{Transition of Oyashio and Kuroshio water properties under the climate change}

We show the future Oyashio and Kuroshio TS profiles from the FORP-NP10 products. The average TS profiles of April and May during 2006-2020, 2041-2060, and 2081-2100 are plotted in Fig. 6. In the four RCP2.6 runs, the scenario the emission decreased from mid-twentyfirst century; only slight changes can be seen both in the Oyashio and the Kuroshio TS profiles. Among the four models, clear shift of Oyashio temperature and salinity shift to high in the mid-twenty-first century can be found in MRI-CGCM3 and MIROC5 in April and MIROC5 in May. On the contrary in the RCP8.5 runs, the scenario the emission keeps increasing toward the end of the twenty-first century; all products show that Oyashio temperature and salinity drastically increase and get closer to the Kuroshio TS profiles by the end of
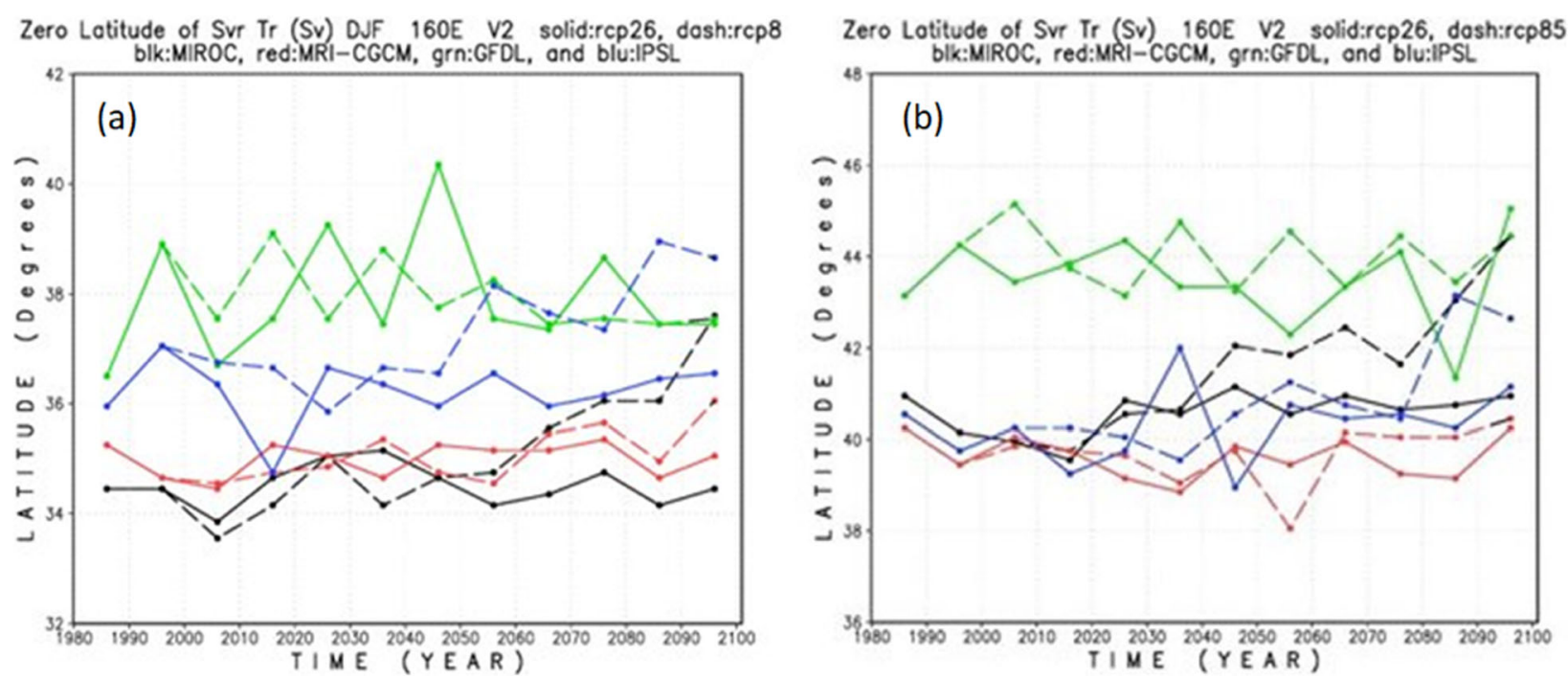

Fig. 5 Time series of zero latitude of Sverdrup transport at $160^{\circ} \mathrm{E}$ calculated from MIROC5 (black lines), MRI-CGCM3 (red lines), IPSL-CM5A-MR (blue lines), and GFDL-ESM2M (green lines) a winter (December, January, and February) mean and $\mathbf{b}$ annual mean wind stress forcing from CMIP5 RCP2.6 (solid lines) and RCP8.5 (dashed lines) experiments. 

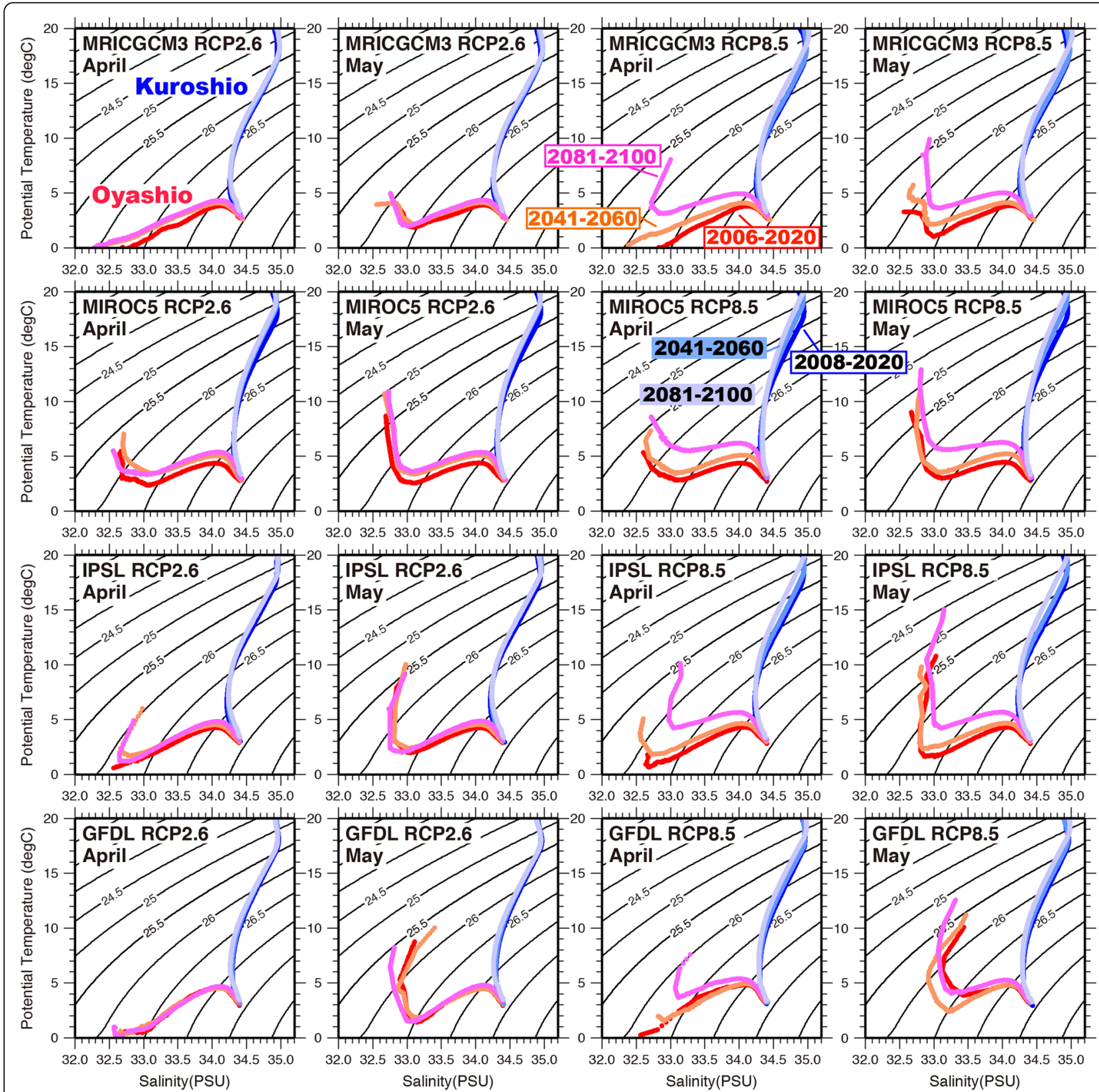

Fig. 6 TS profiles of the pure Oyashio waters (blue) and Kuroshio waters (red) in April and May with four models and two scenarios. Each curve is corresponding to a mean value during 2006-2020, 2041-2060, and 2081-2100

the century. On the other hand, Kuroshio TS profiles show very little change in all simulations through twenty-first century. We concluded that the Kuroshio characteristics of temperature and salinity are robust to the projected climate change, but the Oyashio water properties are very sensitive to the emission scenarios. Although the change of Oyashio TS profiles in RCP8.5 varies with models, all models predict that Oyashio temperature will be over $10{ }^{\circ} \mathrm{C}$ in the end of the twentyfirst century.

\section{Comparison of two front detection methods}

April-May mean latitudes of the Oyashio and Kuroshio fronts detected in two methods for all FORP-NP10 products are shown in Fig. 7. The mean latitudes of the fronts in historical and RCP runs, difference between TS-based and temp-based front latitudes, and difference of latitudes between historical and RCP runs are summarized in Table 1. Both the Oyashio and Kuroshio fronts under RCP8.5 scenario tend to shift northward in the temperature-based estimation and the TS-based 


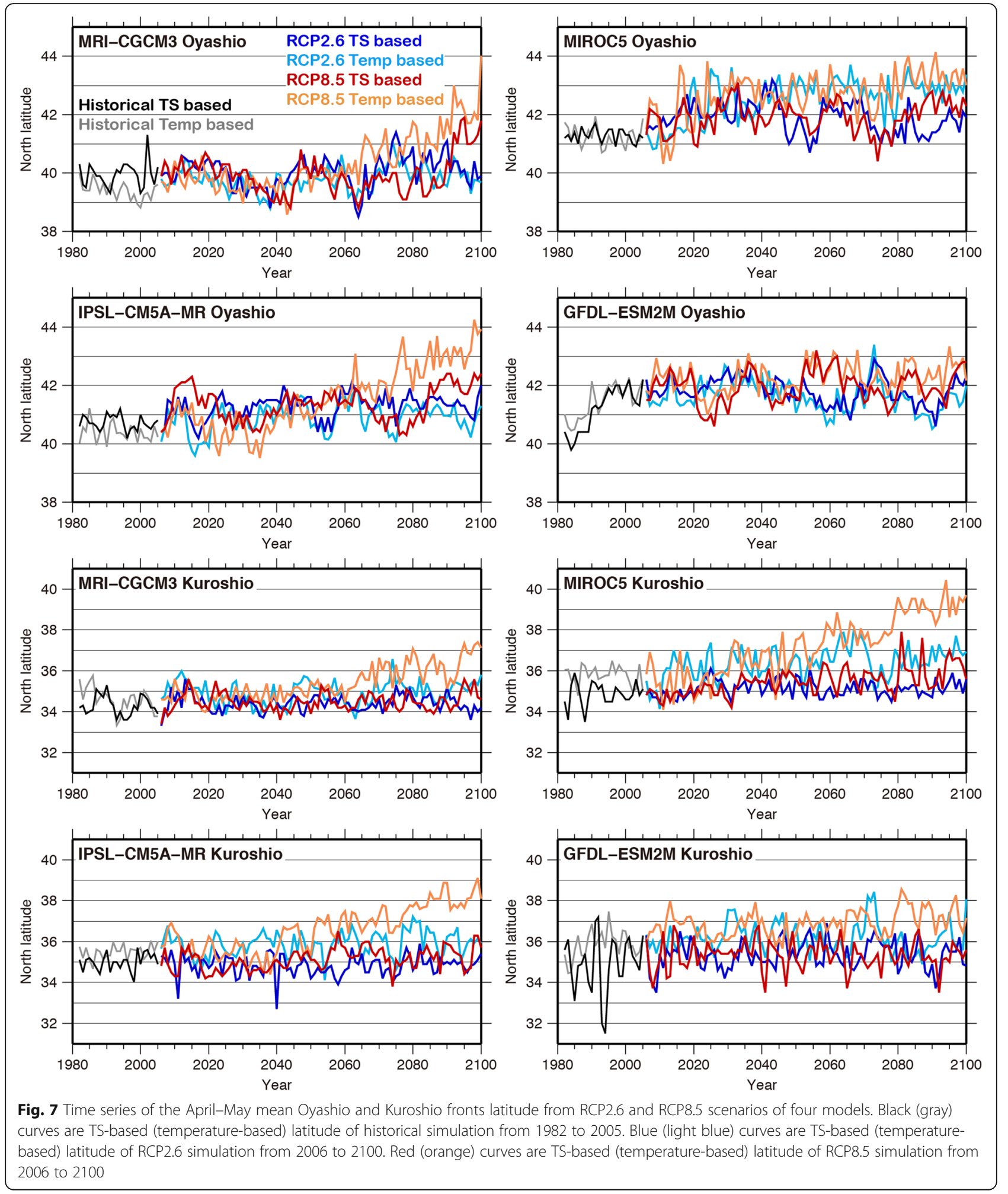

estimation. Notable point is that the shifts by the temperature-based estimation are remarkably larger than the shifts estimated by the TS-based detection method (Fig. 7).
The mean latitudes of the fronts in historical and RCP runs, difference between TS-based and temp-based front latitudes, and difference of latitudes between historical and RCP runs are summarized in Table 1. Both Oyashio 
Table 1 Table caption

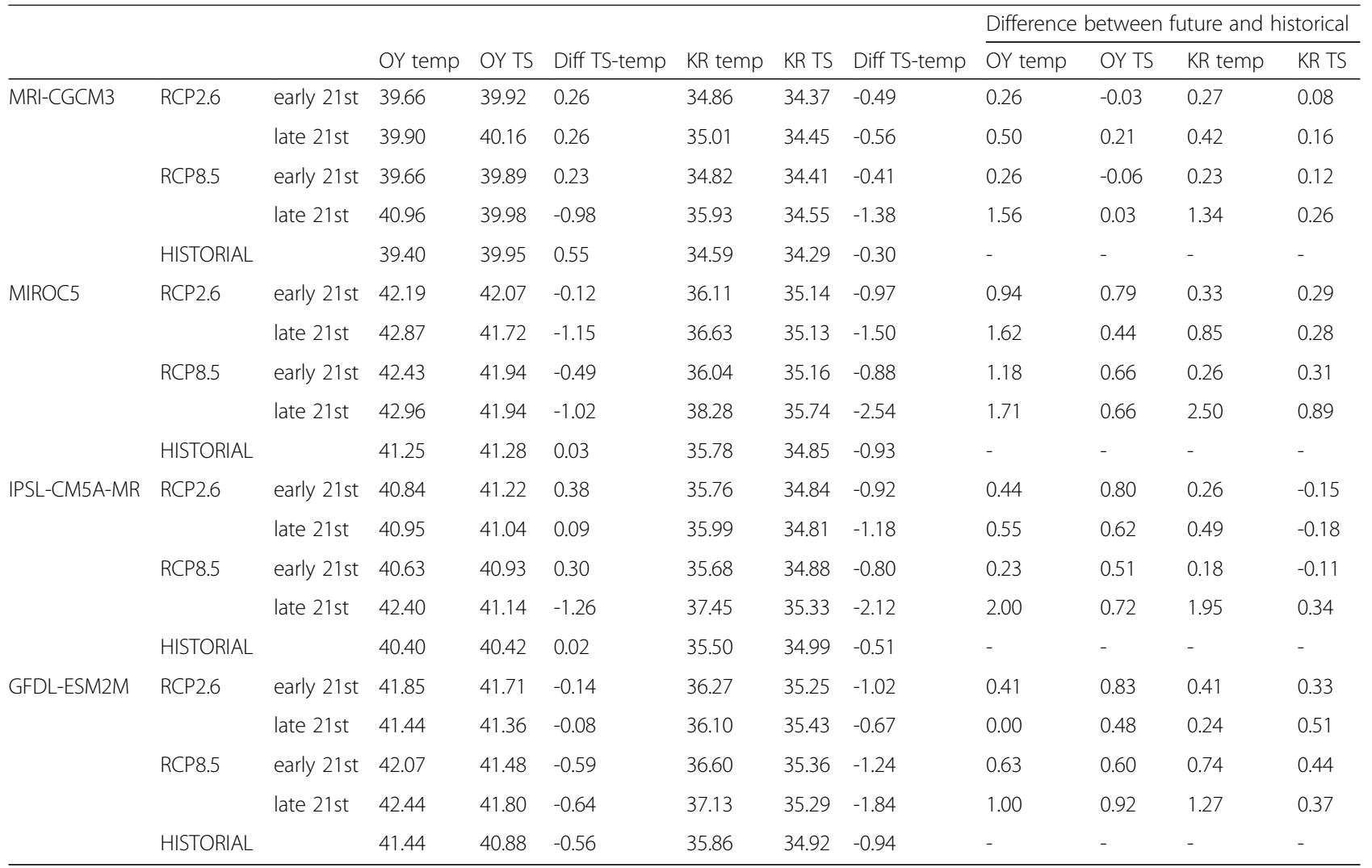

and Kuroshio fronts shift northward in most of the cases. On average of four models, the Oyashio front latitude in the late twenty-first century (2051-2100 mean) is $0.67^{\circ}$ (temperature-based) $/ 0.44^{\circ}$ (TS-based) larger than historical mean in RCP2.6 and $1.57^{\circ}$ (temperaturebased) $/ 0.58^{\circ}$ (TS-based) in RCP8.5. For the Kuroshio front, $0.50^{\circ}$ (temperature-based) $/ 0.19^{\circ}$ (TS-based) larger than historical mean in RCP2.6 and $1.77^{\circ}$ (temperaturebased) $/ 0.46^{\circ}$ (TS-based) in RCP8.5. The northward shifts are larger in RCP8.5 than that in RCP2.6. At the same definition of fronts, there is no significant difference between northing of the Oyashio fronts and the Kuroshio fronts. The degree of northward shift is larger in temperature-based estimation than in TS-based estimation (see the difference between historical and RCP runs in Table 1). Mean latitudes of the Oyashio and Kuroshio fronts tend to be higher in temperature-based estimation than in TS-based estimation (see the difference between temperature-based and TS-based in Table 1).

Since the temperature-based and the TS-based fronts latitudes are significantly different in MIROC5 RCP8.5 case, we plotted surface ocean state from MIROC5 RCP8.5 case in May 2080 in Fig. 8. According to the temperature-based front detection method, the Oyashio front $\left(5{ }^{\circ} \mathrm{C}\right.$ at $\left.100 \mathrm{~m}\right)$ is located in the coastal area of Hokkaido and Kuril Islands and the offshore Kuroshio front $\left(14.5^{\circ} \mathrm{C}\right.$ at $\left.200 \mathrm{~m}\right)$ is located above $40^{\circ} \mathrm{N}$ (Fig. 8a). However, according to the surface velocity field (Fig. $8 \mathrm{~d}$, e), the current continues from the EKC turns to east near $155^{\circ} \mathrm{E}$ and $44^{\circ} \mathrm{N}$, which seems to be corresponding to the Oyashio current. The $100 \mathrm{~m}$ depth temperature in that region is about $9{ }^{\circ} \mathrm{C}$ (Fig. 8b). From Fig. 8e, the Kuroshio main stream is obviously located around $32-$ $37^{\circ} \mathrm{N}$ and the corresponding $200 \mathrm{~m}$ temperature is about $17{ }^{\circ} \mathrm{C}$ (Fig. 8c). On the other hand, the temperature-based Kuroshio front is located around 40$41^{\circ} \mathrm{N}$, along which $200 \mathrm{~m}$ depth salinity is about 34.2 PSU (Fig. 8f). The salinity is obviously too low for the Kuroshio waters.

\section{Discussion}

We estimated transitions of the Oyashio and Kuroshio waters TS profiles and respective front positions under the influence of the projected climate change using the high-resolution regional ocean future projection FORPNP10. The fronts transitions evaluated by two front definition methods, conventional temperature-based method and newly proposed TS-based method, are compared. While the Kuroshio water TS profile is relatively stable in all cases, the Oyashio water TS profile experiences large shift toward high temperature and salinity rapidly in all RCP8.5 cases. Both the Oyashio and Kuroshio fronts tend 


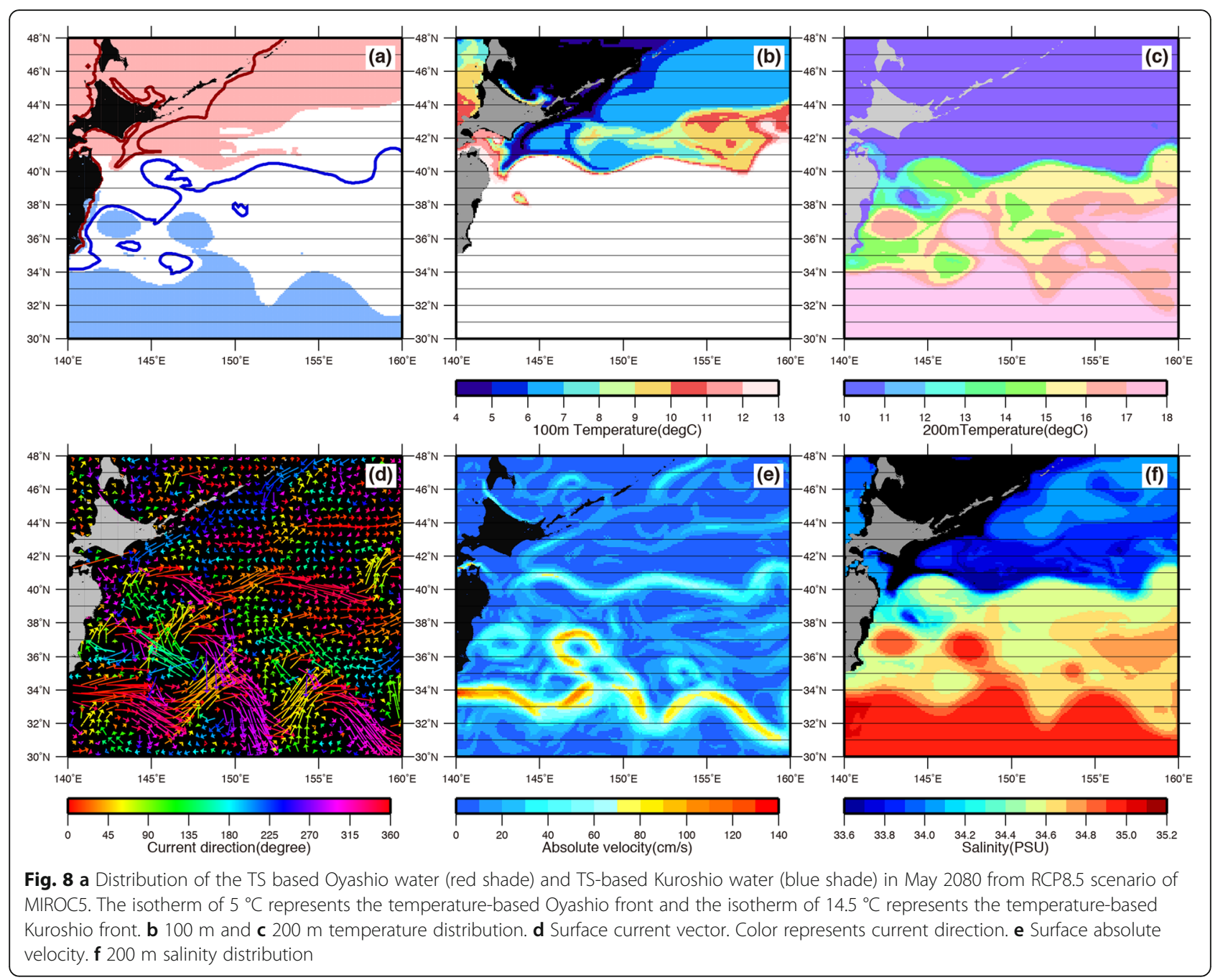

to shift northward in the temperature-based estimation and the TS-based estimation. But the notable point is that the shifts by the temperature-based estimation are remarkably larger than the shifts by the TS-based estimation. In the Oyashio front detection case, temperature change in Oyashio water causes the difference estimates depending on a choice of the detection methods in RCP8.5 cases, too. Due to the Oyashio warming, the Oyashio front looks moving southward from tracking the isotherm of $5^{\circ \circ} \mathrm{C}$ at $100 \mathrm{~m}$, which is the conventional definition of the Oyashio front position.

Since the high-temperature Oyashio waters penetrate into the Kuroshio-Oyashio transition zone, isotherm of $14.5^{\circ} \mathrm{C}$ at $200 \mathrm{~m}$, which is the conventional definition of the Kuroshio front position, appears in the far north from the actual Kuroshio front position as shown in Fig. 8. Thus, the temperature-based front detection method misses the actual front positions under the projected climate change due to global warming impacts. The TSbased estimation also suggests that the Oyashio and
Kuroshio fronts shift northward in all cases, but the latitudinal changes are lower than $1^{\circ}$. For that reason, we recommend the TS-based definition for discussing the Oyashio and Kuroshio front transitions under the projected climate change using FORP-NP10 products. Being aware of temperature and salinity change of the Oyashio and Kuroshio water properties is a key to follow the transitions of the Oyashio and Kuroshio fronts and eventually transitions of water properties of KOTZ under the projected climate change.

As summarized in the previous section, this northward shift tendency is anticipated prior to the ocean downscaling experiments from analysis of the STSF zero latitude based on the CMIP5 wind stress forcing. However, this tendency is noticeable only in the specific set of the forcing, MIROC5 and IPSL-CM5A-MR under RCP8.5 scenario (Fig. 5). Among the FORP-NP10 products, the largest northward shift of about $6^{\circ}$ in the Kuroshio front can be found in the MIROC5 and IPSL-CM5A-MR under RCP8.5 scenario based on the temperature-based 
estimation. However, the corresponding Kuroshio fronts estimated by the TS-based detection method do not show significant northward shift compared to the other models, MRI-CGCM3 and GFDL-ESM2M. In the case of the Oyashio front, its significant northward shift of about $4^{\circ}$ can be seen in MIROC5, IPSL-CM5A-MR, and MRI-CGCM3 under RCP8.5 scenario and minor northward shift of about $2^{\circ}$ in MIROC5 under RCP8.5 scenario based on temperature-based estimation. This pattern is not consistent with the poleward shift of the Oyashio front anticipated from the analysis of the STSM zero latitude in Fig. 5b on which MRI-CGCM does not show significant poleward shift. Further, such clear connection between wind stress and the latitudinal shift of the fronts is missing in the TS-based estimation. These observations tell us that the latitudinal shift of the Kuroshio and Oyashio fronts can be explained partly by the wind stress shift, but transitions in water mass properties have large impact in determining the Kuroshio and the Oyashio fronts under the projected climate change.

According to the TS-based transitions in fronts positions, the latitudinal change of the Oyashio and Kuroshio fronts will not be so drastic as is estimated from the conventional approach. It is possible to say that the impacts of the climate change on the fish migration and fishing grounds location are small from these results. However, we alert that the global warming may have serious impacts on the distribution and stock of fish in the Oyashio and Kuroshio region. At the present time, many fish do the seasonal migration between the Kuroshio and Oyashio region. If their migration ecology depends on temperature, the Oyashio warming will influence on it. Our results are from April to May. Since the Oyashio water has a seasonal cycle in intensity and its distribution (Sekine 1988), the degree of temperature and salinity change in other season may be different from spring. However, we expect that the same change occurs in other seasons. This is a subject for future analysis. We are also concerned about the Oyashio productivity. The nutrient amount in the Oyashio water will decrease. The rich nutrients in the Oyashio water are supplied by the vertical mixing in the upstream Oyashio region. The drastic warming of the Oyashio water will possibly change the nutrient cycle. It is necessary to investigate why the Oyashio water changes, for example, whether the OSMW or the EKC contributes to the Oyashio warming, and how the Oyashio warming will have an impact on the ecology in the Northwestern Pacific in future.

\section{Conclusions}

We show three important results in this study. First, the front latitude of the Oyashio and Kuroshio will shift northward. Second, Oyashio TS profile will drastically change. Third, the fronts positions vary depending on the detecting method, temperature-based or TS-based. The northward shift of the Kuroshio front has already been reported by previous studies. We confirm their results by using the first eddy-resolving CMIP5 model. And this is the first study that suggests the possibility of the Oyashio front northward shift. Also, the Kuroshio and Oyashio TS profiles in the future are firstly estimated in this study. The third results are related to the second one. Our study suggested that since the drastic TS profile change, the conventional front definition based on isotherm distribution will probably be useless in the future. There are no negligible information for studies about impact assessment of global warming.

\section{Authors' contributions}

SN, HI, TW, and YI developed the ocean climate projection products. HN analyzed the model output and wrote the first draft manuscript. SN, HI, and TW provided ideas for the study and helped in interpretation of the model output. SN and TW collaborated with the corresponding author in the construction of the manuscript through several drafts. All co-authors participated in discussions about the results and commented on the manuscript. All authors read and approved the final manuscript.

\section{Funding}

$\mathrm{HN}, \mathrm{SN}, \mathrm{HI}, \mathrm{TW}$, and $\mathrm{Yl}$ are supported by the Social Implementation Program on Climate Change Adaptation Technology (SI-CAT) Grant Number JPMXD0715667163 from the Ministry of Education, Culture, Sports, Science and Technology (MEXT). HN is supported by JSPS KAKENHI Grant number 18K14516. TW is supported by the Nansen Center (NERSC) basic funding.

\section{Availability of data and materials}

The FORA-WNP and FORP data set used in this study is available from the authors upon request. The request URL of FORA-WNP is http://synthesis.jamstec.go.jp/FORA/e/.

\section{Competing interests}

The authors declare that they have no competing interests.

\section{Author details}

${ }^{1}$ Japan Agency for Marine-Earth Science and Technology, 3173-25

Showa-machi, Kanazawa-ku, Yokohama, Kanagawa 236-0001, Japan. ${ }^{2}$ The Nansen Center, Thormøhlens gate 47, 5006 Bergen, Norway. ${ }^{3}$ Bjerknes Centre for Climate Research, Jahnebakken 5, 5007 Bergen, Norway.

Received: 27 December 2019 Accepted: 27 May 2020

Published online: 29 June 2020

\section{References}

Hurlburt H, Wallcraft A, Schmitz W, Hogan P, Metzger E (1996) Dynamics of the Kuroshio/Oyashio current system using eddy-resolving models of the North Pacific Ocean. J Geophys Res 101:941-976. https://doi.org/10.1029/95JC01674

Ichii T, Nishikawa H, Mahapatra K, Okamura H, Igarashi H, Sakai M, Suyama S, Namagmai M, Naya M, Usui N, Okara Y (2018) Oceanographic factors affecting interannual recruitment variability of Pacific saury (Cololabis saira) in the central and western North Pacific. Fish Oceanogr 27:445-457

Kakehi S, Ito S, Wagawa T (2017) Estimating surface water mixing ratios using salinity and potential alkalinity in the Kuroshio-Oyashio mixed water regions. Estimating surface water mixing ratios using salinity and potential alkalinity in the Kuroshio-Oyashio mixed water regions. J Geophys Res Oceans 122: 1927-1942

Kawai H (1972) Hydrography of the Kuroshio Extension. In: Stommel H, Yoshida K (eds) . its physical aspects, Kuroshio, pp 235-352

Kida S, Mitsudera F, Aoki S et al (2015) Oceanic fronts and jets around Japan: a review. J Oceanogr 71(5):469-497. https://doi.org/10.1007/s10872-015-0283-7

Kouketsu S, Yasuda I, Hiroe Y (2005) Observation of frontal waves and associated salinity minimum formation along the Kuroshio Extension. J Geophys Res Oceans: 110

Levitus S, Boyer TP (1994) World Ocean Atlas 1994. Vol. 4. Temperature. NOAA Atlas NESDIS 4. U.S. Government Printing Office, Washington, D.C., p 117 
Levitus S, Burgett R, Boyer TP (1994) World Ocean Atlas 1994. Vol. 3. Salinity. NOAA Atlas NESDIS 2. U.S. Government Printing Office, Washington, D.C., p 99

Li R, Jing Z, Chen Z, Wu L (2017) Response of the Kuroshio Extension path state to near-term global warming in CMIP5 experiments with MIROC4h. J Geophys Res 122(4):2871-2883

Masujima M, Yasuda I, Hiroe Y, Watanabe T (2003) Transport of Oyashio water across the subarctic front into the mixed water region and formation of NPIW. J Oceanogr 59:855-869

Nishikawa H, Usui N, Kamachi M, Tanaka Y, Ishikawa Y (2016) Link between the interanual variability in the Kuroshio-Oyashio layered structure and the chlorophyll-a concentrations in the Kuroshio Extension during spring. Oceanography Japan 25(5):133-144

Nishikawa S, Wakamatsu T, Ishizaki H, Tanaka Y, Ishikawa Y (2020) Development of high-resolution ocean future projection data set around Japan for coastal applications. PEPS submitted

Sakamoto TT, Hasumi H, Ishii M, Emori S, Suzuki T, Nishimura T, Sumi A (2005) Responses of the Kuroshio and the Kuroshio extension to global warming in a high-resolution climate model. Geophys Res Lett 32:14

Sato Y, Yukimoto S, Tsujino H, Ishizaki H, Noda A (2006) Response of North Pacific Ocean circulation in a Kuroshio-Resolving ocean model to an arctic oscillation (AO)-like change in Northern hemisphere atmospheric circulation due to greenhouse-gas forcing. J Meteorol Soc Jpn 84(2):295-309

Seager R, Kushnir Y, Henderson N, Cane M, Miller J (2001) Wind-driven shifts in the latitude of the Kuroshio-Oyashio extension and generation of SST anomalies on decadal timescales. J Clim 14:4249-4265. https://doi.org/10. 1175/1520-0442(2001)014<4249:WDSITL>2.0.CO:2

Sekine Y (1988) Anomalous southward intrusion of the Oyashio east of Japan: 1. Influence of the seasonal and interannual variations in the wind stress over the North Pacific. J Geophys Res Oceans 93:2247-2255

Shimizu, Y., Yasuda, I., and Ito, S. (2001) Distribution and circulation of the coastal Oyashio intrusion. Journal of Physical Oceanography, 31, 1561-1578.

Taylor KE, Stouffer RJ, Meehl GA (2012) An overview of CMIP5 and experiment design. Amer Meteor Soc 93:485-498. https://doi.org/10.1175/BAMS-D-1100094.1

Tsujino H, Nakano H, Sakamoto K, Urakawa S, Hirabara M, Ishizaki H, Yamanaka G (2017) Reference manual for the Meteorological Research Institute Community Ocean Model version 4 (MRI.COMv4). Technical Reports of the MRI 80.

Usui N, Wakamatsu T, Tanaka Y, Hirose N, Toyoda T, Nishikawa S, Fujii Y, Takatsuki Y, Igarashi H, Nishikawa H, Ishikawa Y, Kuragano T, Kamachi M (2017) Fourdimensional variational ocean reanalysis: a 30-year high-resolution dataset in the western North Pacific (FORA-WNP30). J Oceanogr 73:205-233

Yang H, Liu J, Lohmann G, Shi X, Hu Y, Chen X (2016) Ocean-atmosphere dynamics changes associated with prominent ocean surface turbulent heat fluxes trends during 1958-2013. Ocean Dyn 66(3):353-365

Yasuda I, Hiroe Y, Komatsu K, Kawasaki K, Joyce TM, Bahr F, Kawasaki Y (2001) Hydrographic structure and transport of the Oyashio south of Hokkaido and the formation of North Pacific Intermediate Water. J Geophys Res Oceans 106:6931-6942

Yokouchi, K., Tsuda, A., Kuwata, A., Kasai, H., Ichikawa, T., Hirota, Y., Adachi, K., Asanuma, I. and Ishida, H. (2006) Simulated in situ measurements of primary production in Japanese waters. pp. 65-88 in global climate change and response of carbon cycle in the equatorial pacific and Indian oceans and adjacent landmasses edited by K. Kawahata and Y. Awaya, Elsevier, Amsterdam

Zhang RC, Hanawa K (1993) Features of the watermass front in the Northwestern North Pacific. J GeophysRes 98C:967-975

\section{Publisher's Note}

Springer Nature remains neutral with regard to jurisdictional claims in published maps and institutional affiliations.

\section{Submit your manuscript to a SpringerOpen ${ }^{\circ}$ journal and benefit from:}

- Convenient online submission

- Rigorous peer review

- Open access: articles freely available online

- High visibility within the field

- Retaining the copyright to your article

Submit your next manuscript at $\boldsymbol{\nabla}$ springeropen.com 